\title{
An academic pathological dilemma
}

\author{
Helmut H. Popper
}

Received: 21 January 2014 / Accepted: 6 May 2014 / Published online: 3 June 2014

(C) Springer-Verlag Wien 2014

This editorial is based on personal communications with colleagues, visits to Pathology Departments in several EU and non-EU countries. The statements within this editorial represent my personal assessment of the present situation of Pathology in Europe and are in no context with any of my functions in Pathology organizations.

Modern medicine is based on the systematic identification of diseases and the profound knowledge of the underlying pathogenic processes. Without a valuable diagnostic tool we would fail in our struggle to help our patients. Facing such basic principles of medicine, recent developments reported from different pathology departments at medical universities are alarming. Indicators of this development are the decreasing number of young doctors willing to start the training to become a pathologist and the increasing number of experienced pathologists who leave universities to work at private institutes.

The reasons for this development are manifold, the potential threats should be kept in mind and possible strategies to fight this trend should be developed.

\section{Academic pathologists-a vanishing species}

In the last 2 decades, traditional molecular pathology has gained an increasing impact on pathology in almost every aspect of diagnostics, as well as research. The increasing importance of targeted therapy has shifted pathology from a diagnostic discipline with some aspects on prognosis back into the center of clinical management. By analyzing the molecular background of malignan-

Prof. H. H. Popper, MD ( $\square)$

Medical University Graz,

Auenbruggerplatz 25,

8036 Graz, Austria

e-mail: helmut.popper@medunigraz.at cies, the pathologist has developed to be a central player in the interdisciplinary cancer team, who decides about patient's management and treatment. Despite this bright future, pathology departments all over the world complain that fewer and fewer young medical doctors are interested in starting a career as a pathologist. Around 2 decades ago, we had 5-9 applicants-interested in pursuing pathology-for each vacant position at our institution and the best qualified was chosen in those times. Now, we are happy to find at least one interested doctor to fill this gap!

There are several reasons, which might have induced this development:

1. The teaching curriculum at medical universities in many European countries has changed. New disciplines have been introduced; more time has been reserved for social competency, communication with patients, and more lessons in behavioral sciences. On the other hand, the European Commission has forced member states to reduce the time for medical studies. Consequently, natural science disciplines were reduced in time. For pathology, this resulted in a dramatic reduction of teaching lessons. In the 1980-ties pathology was represented by $5 \mathrm{~h}$ per week general lessons during 4 semesters. A lot of special lessons on organ pathology and practical seminars on autopsy and histology were provided. In 2005 pathology was reduced to a 5-week seminar, a few practical courses and some scarce interactions with clinical disciplines. Nowadays, students are much less exposed to pathology than ever before. So how should a student be able to explore the importance of pathology?

2. The workload of pathologists has increased substantially over time, but the number of staff members has constantly decreased. Thus, an increasing number of histological subtypes have to be differentiated requiring a high expertise in sub-specialties, which has 
made routine diagnostic work-up much more timeconsuming. Furthermore, in most European countries student teaching is part of the duties of the staff members of the Department. Performing lectures is calculated into the workload, but preparation for teaching is not. So pathologists are switching between diagnostics and teaching. All these points might result in a decreased engagement in teaching, less engagement in curricular commissions and consequently in fewer lectures. All this has lead to the fact that fewer students can be recruited for a potential pathological career.

3. In academic departments research is a central part of the duties and the career of a pathologist is mainly based on her/his publication record. However, financial resources, especially for clinical projects, have constantly decreased making pathology-dominated scientific activities nearly impossible for the younger generation. With the exception of large consortia, basic equipment and basic scientific staff is rarely offered by a standard academic institution.

4. Payment of medical doctors at universities and major teaching hospitals is being constantly reduced. In pathology there is usually no extra income, no services at night, no weekend services for which clinical doctors get extra payment. The deal offered to applicants is less salary for an increasing workload. Moreover, new academic careers are marked by a hire and fire policy, originally intended to select only the fittest. But, facing the long time period a pathologist needs to get the high experience needed at high-end medical centers, such a policy is contra-productive. Those young doctors, who are still working at academic institutes, face a private industry of pathology services offering salaries which are at least twice as much as earned at a university. Additionally, their job is guaranteed for many years without struggles in teaching and research. As soon as young trainees have finished board examination and some extra training in subspecialties, many of them move into private institutions.

5. The more universities are released into self-organization and financing, the more administrative jobs are created. The major focus of these administrative bodies is to create a very cost-effective structure. Getting more tissues diagnosed by less staff members will increase the income of the University Hospital. In an administrative consideration, research is regarded as non-productive and resource-consuming. Long-term calculation that research is the future for innovation is not in the focus of managers, who are generally engaged for a short period of time.

6. In some countries, the attractiveness of pathology is reduced by the fact that molecular pathology has been outsourced to other departments and the fascinating world of genetics, biology, and disease causes has been taken away. So what interests should attract a young medical doctor into pathology, H\&E pathology?

\section{A medical future without pathological background?}

For university departments the above mentioned development might lead to an uncertain future questioning the fundamental role of pathologists for university hospitals. As pathology departments lose their well-educated staff, the next generation of pathologists cannot be trained adequately. In addition, the more complex workup and the need for extended knowledge in a university department are due to the selection of patients with complicated and sometimes rare diseases. Thus, pathologists sub specialized in organ pathology are urgently needed. However, if personnel are reduced and workload is increased, this sub-specialization will not occur. If experienced staff members are lost to private practices, who is going to teach the next generation? Who should attend the interdisciplinary boards and help to solve complex diagnostic cases? Who should perform bio-banking to enable translational research activities of clinicians? Would we face a future, where human tissue is sent to centralized institutions losing every option for future scientific efforts at medical universities?

Failing to attract our own students to start a pathologist career triggered off an east to west brain drain. A young medical doctor with some training in pathology, or a board examined pathologist in an Eastern country of the EU can easily come to Middle or Western European countries, get a license to work and will be honored by a higher salary, compared to his home country. This is what happens with young Polish pathologists, seeking positions in the UK or Germany, or Hungarian pathologists moving to Sweden. It will be followed by other EU countries, for example France, where a significant amount of pathologists are over the age of 50 and not enough young pathologists are moving into training. But, who would serve the patients in their original home countries. From an ethical point of view, we should scrutinize a development where a mismanagement of a developed and rich country is going to be compensated by a poorer state. But, similar developments can already be seen in industrialized countries like Spain, too. Financial problems have resulted in a reduction of positions in state hospitals. There are numerous young well-trained pathologists who are forced to leave their country.

In some countries, the state authorities have not even realized the need of well-trained pathologists. There are still European countries, where pathologists are serving in up to three or four hospitals, such as Russia. But there are no actions taken by the Government to change this situation. Training of pathologists requires not only the classical training as in other disciplines, usually between 4 and 6 years, but also training in subspecialties within pathology. After finishing his/her training with a board examination, a pathologist will still need training with more experienced members of the team. To reach an expert level in a sub-discipline, like hemato-pathology or pulmonary pathology will take another 4 years of training. This means that becoming a specialist for a major 
teaching hospital or a university department requires up to 10 years of training.

\section{Actions to be taken}

As an elderly pathologist, it is my privilege to offer some ideas, on which, actions could be taken to offer a brighter future for an academic pathology in Europe.

- First of all, it is our task to teach the fascinating challenges of this subject. The present medical students represent the future of this area of expertise.

- Secondly, academic institutions would be well advised to offer long-term perspectives for a medical career to young pathologists with salaries comparable to other medical disciplines. The younger generation is not exclusively interested in earning as much as possible. An interesting career and a mixture of routine work-up, teaching, and research activities are attractive attributes of an academic job description. However, all these tasks should be backed up by adequate resources as regards time, staff, and infrastructure.

- Thirdly, it is necessary to invest money to develop attractive working conditions. It is obvious that modern institutions have much better chances to attract young academics. Adequate working structures are vital preconditions for professional work.

\section{Conflict of interest}

The author declares that there are no actual or potential conflicts of interest in relation to this article. 